\title{
Refined Analysis of User Load Based on Weighted Fuzzy Clustering
}

\author{
J.FAN ${ }^{1,2}$ \& X.L.GAO ${ }^{1,2}$ \& X. CHEN ${ }^{1,2}, K_{.}$SHI $^{3}, P . X^{4}$ \& H. YE ${ }^{4}$ \\ ${ }^{1}$ Jiangsu Electric Power Company Research Institute. Nanjing 211103, China; \\ ${ }^{2}$ State Grid Key Laboratory of Electric Power Metrology, Nanjing 211103, China \\ ${ }^{3}$ Electric Power Research Institute. Beijing, China \\ ${ }^{4}$ North China Electric Power University, Beijing,China
}

\begin{abstract}
KEYWORD: Refined Analysis; Weighted Fuzzy Clustering; Load Classification Dividing; Clustering Efficiency Estimating

ABSTRACT: As the development of intelligent power system, much importance and requirement have been attached to the load data analysis. In view of the current rough classification of load data, propose a weighted fuzzy clustering algorithm to detail the load classification dividing, which adds a weight distribution process to balance the different influence of various factors. In addition, Two group of experiments are set to verify the efficiency of this method. The experiment results show that the algorithm is effective to accurately cluster the load data and supportive to the fine analysis of load data.
\end{abstract}

\section{Introduction}

Influenced by various factors, power system load changes constantly with time. Also, it has the characteristics of continuity and periodicity ${ }^{[1]}$. Power system load characteristic is refers to the characteristics and nature of power load, different types of users load show different load characteristics. To master the characteristics and variation law of power load can be beneficial to safe and steady operation of electric power system and get the best economic benefit for power supply departments. Besides, it can give full play to the benefit of every once electricity for the user ${ }^{[2]}$.

Power system load has strong periodicity as well as randomness ${ }^{[3]}$. On one hand, development trend of power load changes obeying a certain regulation; on the other hand load, certain fluctuations may occur at any moment with society, economy, politics, weather, and many other complicated factors. Load analysis and load distribution management is the foundation of economic analysis of power distribution system. Under the control environment, load analysis mainly serves for load forecasting, system planning and demand side management providing information ${ }^{[4]}$. While in the retail market, which is customer-centric, service strategy, it is more vital to make a refined analysis on the user load characteristic, to help fine mining potential value of electricity characteristics ${ }^{[5]}$.

\section{Index of user load performance}

At present, according to the historical development and current situation in our country a set of relatively comprehensive load characteristic index system has been put forward ${ }^{[6]}$. The index system contains several indexes involving different time ranges from daily to year. The representation mainly divides into numerical type and curve type. Some indexes reflect the overall situation of load characteristics, mainly applied on horizontal comparison between different regions at home and abroad. The others are specific load index, mainly applied on the analysis and calculation of power system planning and design ${ }^{[7]}$. Considering practicality this article uses the index system in table 1 .

However, the utilization of power indexes is still not enough in our country. For instance, the user load usually is roughly divided into several types: load of industry, agriculture, commercial and city life, which just considered the difference between vocations but not accurate indexes. To achieve fine management of user-side, the rough classification could not meet the sharply developing load mining requirement. For instance, user load varies not only with the vocations. Much more issues should be taken into consideration, since even the users of the same profession. Their load performance also may be different from each other due to the weather and personal habits ${ }^{[8]}$. Therefore, an accurate 
and reasonable analysis of power load data needs the detailed classification with more considered issues and more effective algorithms.

Tab.1 Indexes of load data

\begin{tabular}{lll}
\hline Indexes of description & Indexes of comparison & Indexes of curves \\
\hline Maximum/minimum load daily & Minimum load ratio daily & Curve of daily load \\
Average load daily & Average load ratio daily & Curve of year load \\
Difference of daily load & Load ratio difference daily & \\
Maximum/minimum load monthly & Load ratio monthly & \\
Average load daily monthly & Average load ratio monthly & \\
Maximum/minimum load yearly & Minimum load ratio monthly & \\
& Average day load ratio yearly & \\
& Average month load ratio yearly \\
Difference of year load & Load ratio seasonal & \\
& Difference ratio yearly & \\
& Load ratio yearly & \\
& Peak load points of year & \\
\hline
\end{tabular}

\section{Weighted fuzzy clustering}

\section{Preprocessing of load data}

\section{Abnormal data identification and process}

Load data is often not comprehensive collected or distorted due to the signal interference, software failure, equipment performance and so on. Thus, the transverse recognition is used to identify and handle the abnormal data.

A common agreement here is that the load data in a period is probably similar, namely the load curve of sampled day and near similar days are kindly the same. Thus, the abnormal data can be recognized by comparison of sampled data and anticipated result.

Step 1 calculate the mean and variance of data sequence.

$$
\begin{aligned}
& \bar{x}_{n, i}=\frac{1}{N} \sum_{n=1}^{N} x_{n, i}, i=1 \sim 96 \\
& \sigma_{i}^{2}=\frac{1}{N} \sum_{n=1}^{N}\left(x_{n, i}-\bar{x}_{n, i}\right)^{2}
\end{aligned}
$$

Step 2 recognize the abnormal data with threshold (commonly 1-1.5).

$$
\left|x_{n, i}-\bar{x}_{n, i}\right|>3 \sigma_{i} \varepsilon
$$

Step 3 correct the data using weight distribution.

$$
x_{n, i}^{*}=\frac{\alpha_{1}}{2} \sum x_{n \pm 1, i}+\frac{\beta_{1}}{2} \sum x_{n, i}^{1,2}+\gamma_{1} \bar{x}_{n, i}
$$

Here $x_{n, i}$ is the abnormal data. $\alpha_{1}+\beta_{1}+\gamma_{1}=1, x_{n, i}^{*}$ is the corrected data and $x_{n, i}^{1,2}$ is the nearest similar load data from sample.

\section{Range normalization}

To obtain a standardized data sequence, an effective method is the range normalization.

$$
\begin{aligned}
X^{R} & =\left[\begin{array}{cccc}
x_{11}^{R} & x_{12}^{R} & \mathrm{~L} & x_{1 p}^{R} \\
x_{21}^{R} & x_{22}^{R} & \mathrm{~L} & x_{2 p}^{R} \\
\mathrm{M} & \mathrm{M} & & \mathrm{M} \\
x_{n 1}^{R} & x_{n 2}^{R} & \mathrm{~L} & x_{n p}^{R}
\end{array}\right] \\
x_{i j}^{R} & =\frac{x_{i j}-\min _{1 \leq k \leq p} x_{i k}}{\max _{1 \leq k \leq p} x_{i k}-\min _{1 \leq k \leq p} x_{i k}}, i=1,2, \ldots, n ; j=1,2, \ldots, p
\end{aligned}
$$

The $\min _{1 \leq k \leq p} x_{i k}$ here is minimum value of $X_{i}$, and $X^{R}$ is the normalized matrix. 


\section{Weight distribution of load data}

In the normal clustering algorithm, each performance character vector has the same effect weight, which doesn't suit the real situation that the different factor has different effects. Moreover, the effect weight also varies with the user type, conditions and so on. Thus weight distribution is needed to overcome the limitations of direct clustering analysis.

Considering the reference policies and real load characteristics, the TOU (time of use) price is a typical factor to which the load data has great relation. Power price with different weight may illustrate the relationship more accurately. Generally, set a high weight to the working period while a lower for the night rest period.

For instance, the weight of period with high load ratio (8:00-12:00, 17:00-21:00) here is 3 , and that of rest period is as default value 1. In addition, this method is also suitable for other vectors to reflect their true effectiveness to the load data.

\section{Fuzzy clustering process}

The main principle of FCM algorithm is to iterate and adjust $(U, V)$ to get a minimum objective function $\mathrm{J}$. The detailed steps are as following ${ }^{[9]}$ :

Step 1 Set expected cluster numbers $C$, fuzzy index $\mathrm{m}$ and initial clustering center $\mathrm{v}_{0}^{\mathrm{L}}$.

Step 2 Calculate the distance matrix $D$.

Step 3 Calculate the membership matrix $U_{\mathrm{L}}$ according to $D$.

$$
u_{i j}=\frac{1}{\sum_{k=1}^{c}\left(\frac{d_{i j}^{2}}{d_{k j}^{2}}\right)^{1 / m-1}}
$$

Step 4 Calculate the clustering center $V_{L+1}$ according to $U_{L}$.

$$
v_{i}^{L+1}=\frac{\sum_{j=1}^{n}\left(u_{i j}{ }^{L}\right)^{m} x_{j}}{\sum_{j=1}^{n} u_{i j}^{L}(k)^{m}}
$$

Step 5 Make a judgment of whether $\left\|U^{L+1}-U^{L}\right\|<\varepsilon$, if it sets up, the process break up, otherwise back to step 2 and goes on.

About the expected cluster numbers $C$, its value haven't had an accurate setting. While Pal and Bezdek point out that the maximum limitation is that $c_{\max } \leq \sqrt{n}$, as $\sqrt{n}$ increases much faster than $\ln n$, we set $c_{\max } \leq 2 \ln n$.

About the initial clustering center $V$, it is well known that the clustering result is much sensitive to initial center. Not only has the classification varied largely with different center initialization, an unexpected minimum point may also appears to lead to a slow constriction even an endless loop. Thus, the special factors are extracted to avoid that.

\section{Clustering efficiency estimating}

A probability distribution based clustering efficiency function is applied here as the evidence of clustering result estimating ${ }^{[10]}$. The function mainly achieves the judgment via probability distribution function $F(U, c)$ and coefficient $P(U, c)$. For each sampled $X_{\mathrm{i}}$, the probability distribution function $F(U, c)$ and coefficient $P(U, c)$ is as following ${ }^{[11]}$.

$$
\begin{gathered}
F(U ; c)=\frac{1}{n} \sum_{j=1}^{n}\left(\sum_{i=1}^{c} \mu_{i j}^{2} / \sum_{i=1}^{c} \mu_{i j}\right) \\
P(U ; c)=\frac{1}{c} \sum_{i=1}^{c}\left(\sum_{j=1}^{n} \mu_{i j}^{2} / \sum_{j=1}^{n} \mu_{i j}\right)
\end{gathered}
$$

For the given $U$ and $c$, clustering efficiency function is as following (11), and the optimal result appears when it suits the condition of equation (12).

$$
F P(U ; c)=F(U ; c)-P(U ; c)
$$




$$
F P\left(U^{*} ; c^{*}\right)=\min _{c}\left\{\min _{\Omega_{c}} F P(U ; c)\right\}
$$

\section{Simulation and fine analysis}

To study the load performance of a user with different situation, select an electronic component produce company as object, sampling its load data of April, June to September, 2010 with 24 points daily, totally 152 sets of data with 130 of them are available. The clustering result is as Fig.1.

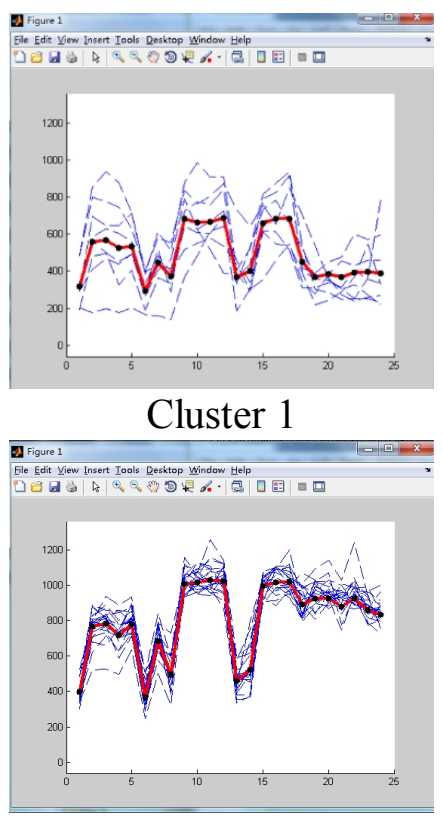

Cluster 3

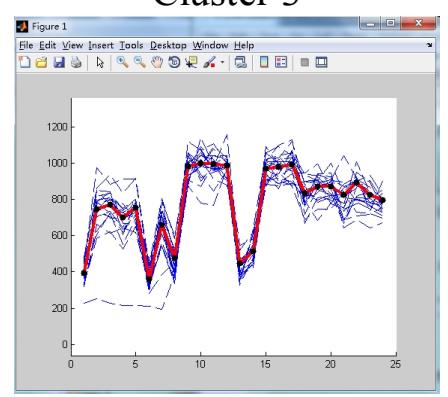

Cluster 5

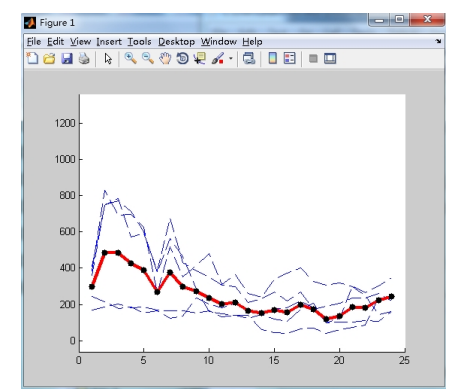

Cluster 2
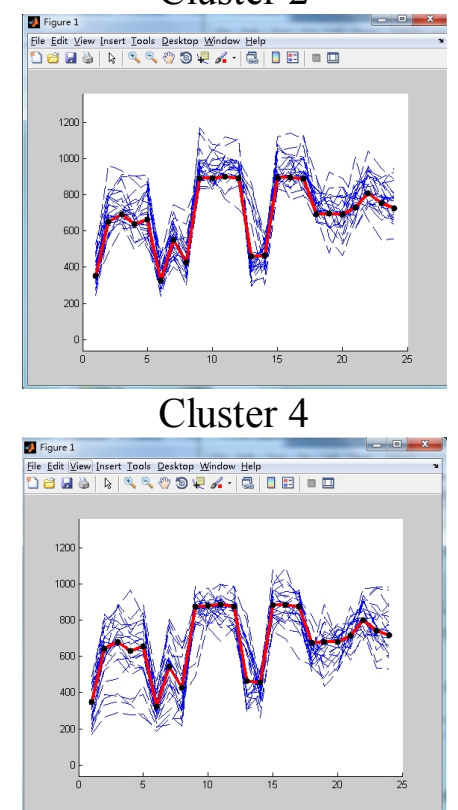

Cluster 6

Figure 1. Clustering results of specific company

Tab.2 refined analysis of load utilization from one company

\begin{tabular}{|c|c|c|}
\hline Industry type & & Electronic manufacture \\
\hline Load performance & & Oscillation when folk shift \\
\hline Peak point & & $2,8-11,14-16$ \\
\hline Adjustable load for climate & & Little related to climate \\
\hline Adjustable load for production & Level 1 & $200-300 \mathrm{~kW}$ \\
\hline Suitable demand response strategy & Level 2 & $\begin{array}{l}500-600 \mathrm{~kW} \\
\text { TOU price, critical peak price, interrupt- } \\
\text { ible load, emergency demand response } \\
\text { strategy }\end{array}$ \\
\hline
\end{tabular}

Integrating the above load clustering results, it can be known that the company works in three shift system. However, there exists a temporary oscillation when the folk hand over. That means, part of the production devices are not necessary to work constantly. So we can guess that when power grid is overloaded, these devices can be rest to lower the load. For each class, the first two classes 
seem special to the others. According to their load values, class 1 and 2 seems to be in low production situation. Under normal production situation, the top load ranges from $800 \mathrm{~kW}$ to $1200 \mathrm{~kW}$, not varying as the season shifts. There exist almost $200-300 \mathrm{~kW}$ reasonable load and $500-600 \mathrm{~kW}$ safe load available to adjust the load level. Therefore, we can predict that the company would be willing to transfer a portion of load into night period as the price motivation. In summary, the detailed analysis of user power consumption behaviors is as the following Tab.2.

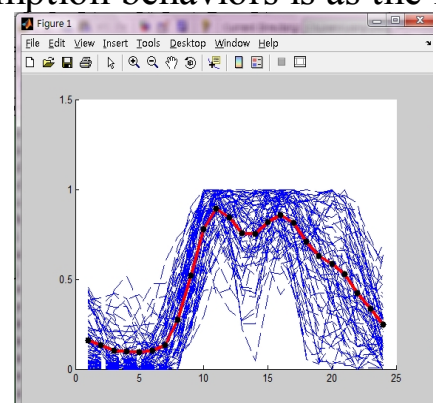

Cluster 1

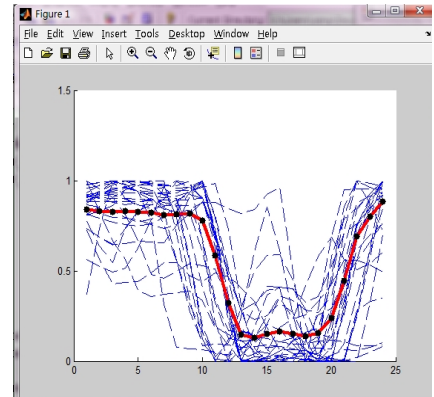

Cluster 3

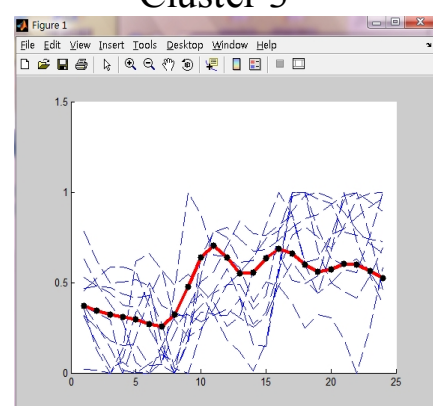

Cluster 5

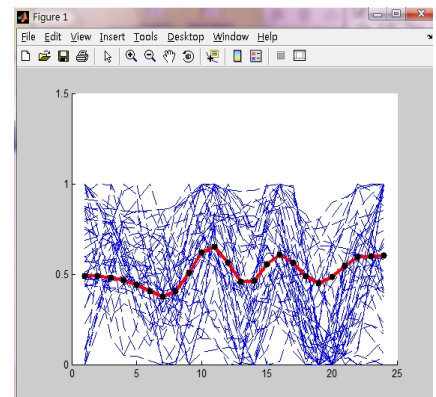

Cluster 7

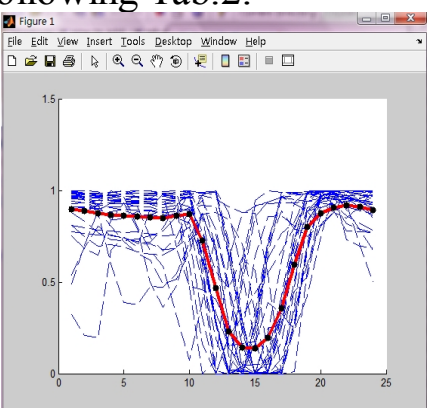

Cluster 2

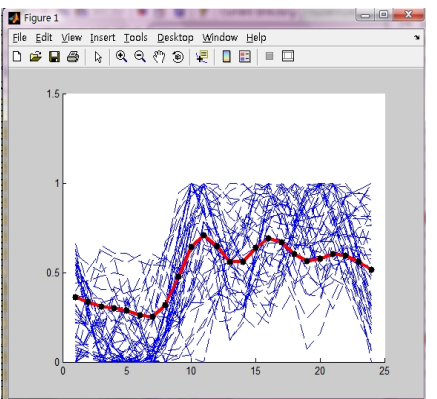

Cluster 4

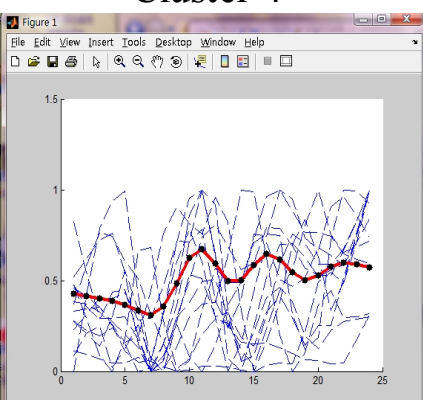

Cluster 6

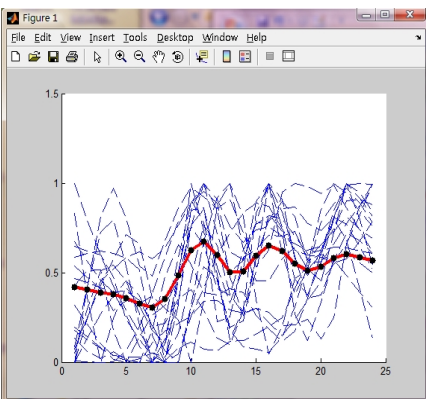

Cluster 8

Fig.2 Clustering results of different industries

Moreover, a set of load data from different companies at the same time are also analyzed to study the load difference among different industries. Here selected 386 companies as the sample with 24 points a day each. The temperature is $15^{\circ} \mathrm{C}$ and 264 data sets are available. The simulation result is shown in Fig.2.

From the above cluster results, it can be seen that the first class represents the typical companies which products in the day and rests at night, containing the $27 \%$ of all companies, such as comprehensive retail and tourism hotel industry. In view of their power transferring ability, the lighting and air conditioner are the main available devices to adjust power utilization. Therefore, critical peak 
pricing and direct load control may be effective to them but with limited ability. While the second and third classes is reversed, which work at night and rest in day. It means that these companies have adapted some strategies to avoid the top price period. The companies of these classes, such as cement manufacturing, textile industry, non-metal manufacturing and so on, have little potential to be exploited. The other companies mainly work in triple shift schedule, which constantly works with 24 hours, however the production in the day is still a little higher. If their production could be changed, the adjustable potential are considerable. The refined analysis of load utilization is as the following tables.

Tab.3 indexes of load data performance from different classifications

\begin{tabular}{cccccc}
\hline $\begin{array}{c}\text { Classifi- } \\
\text { cation }\end{array}$ & $\begin{array}{c}\text { Daily load } \\
\text { ratio }\end{array}$ & $\begin{array}{c}\text { Minimum } \\
\text { load ratio } \\
\text { daily }\end{array}$ & $\begin{array}{c}\text { Difference } \\
\text { of load dai- } \\
\text { ly }\end{array}$ & $\begin{array}{c}\text { Peak } \\
\text { hour }\end{array}$ & $\begin{array}{c}\text { Valley } \\
\text { hour }\end{array}$ \\
\hline 1 & $54.1 \%$ & $10.6 \%$ & $89.3 \%$ & 10 & 4 \\
2 & $76.2 \%$ & $14.9 \%$ & $85.2 \%$ & 21 & 14 \\
3 & $62.2 \%$ & $14.6 \%$ & $85.4 \%$ & 23 & 13 \\
4 & $70.8 \%$ & $35.5 \%$ & $64.4 \%$ & 10 & 6 \\
5 & $71.3 \%$ & $36.6 \%$ & $63.4 \%$ & 10 & 6 \\
6 & $75.3 \%$ & $46.3 \%$ & $53.7 \%$ & 10 & 6 \\
7 & $78.6 \%$ & $57.7 \%$ & $42.2 \%$ & 10 & 6 \\
8 & $74.8 \%$ & $45 \%$ & $54.9 \%$ & 10 & 6 \\
\hline
\end{tabular}

Tab.4 refined analysis of load data from different vocations

\begin{tabular}{|c|c|c|c|c|}
\hline Vocation & $\begin{array}{l}\text { Classifica- } \\
\text { tion }\end{array}$ & Ratio & Load type & Suitable demand-response strategy \\
\hline \multirow{3}{*}{ Business } & 1 & $61 \%$ & Peak forward & Critical Peak Pricing, direct control \\
\hline & 4 & $29 \%$ & Constant & $\begin{array}{l}\text { TOU price/Critical Peak Pric- } \\
\text { ing/direct control }\end{array}$ \\
\hline & 8 & $7 \%$ & Constant & $\begin{array}{l}\text { TOU price/Critical Peak Pric- } \\
\text { ing/direct control }\end{array}$ \\
\hline \multirow{3}{*}{$\begin{array}{l}\text { Electronic } \\
\text { production }\end{array}$} & 1 & $35 \%$ & Peak forward & TOU price/interruptible load \\
\hline & 7 & $20 \%$ & Constant & Interruptible load \\
\hline & 4 & $14 \%$ & Constant & Interruptible load \\
\hline \multirow{3}{*}{$\begin{array}{l}\text { Metal indus- } \\
\text { try }\end{array}$} & 1 & $41 \%$ & Peak forward & $\begin{array}{l}\text { TOU price/Critical Peak Pric- } \\
\text { ing/interruntible load }\end{array}$ \\
\hline & 3 & $18 \%$ & Peak avoiding & Emergency demand-response \\
\hline & 4 & $14 \%$ & Constant & $\begin{array}{l}\text { Interruptible load/ emergency demand } \\
\text { response }\end{array}$ \\
\hline \multirow{3}{*}{$\begin{array}{l}\text { Textile indus- } \\
\text { try }\end{array}$} & 2 & $22 \%$ & Peak avoiding & Emergency demand-response \\
\hline & 3 & $19 \%$ & Constant & $\begin{array}{l}\text { Critical Peak Pricing/ interruptible } \\
\text { load/ emergency demand-response }\end{array}$ \\
\hline & 7 & $18 \%$ & Constant & $\begin{array}{l}\text { Critical Peak Pricing/interruptible } \\
\text { load/ emergency demand-response }\end{array}$ \\
\hline \multirow{3}{*}{$\begin{array}{l}\text { Non-metal } \\
\text { industry }\end{array}$} & 7 & $54 \%$ & Constant & Interruptible load \\
\hline & 1 & $15 \%$ & Peak forward & TOU price/interruptible load \\
\hline & 2 & $15 \%$ & Peak avoiding & Interruptible load \\
\hline
\end{tabular}

From the above cluster results, it can be seen that the first class represents the typical companies which products in the day and rests at night, containing the $27 \%$ of all companies, such as comprehensive retail and tourism hotel industry. In view of their power transferring ability, the lighting and air conditioner are the main available devices to adjust power utilization. Therefore, critical peak pricing and direct load control may be effective to them but with limited ability. While the second and third classes is reversed, which work at night and rest in day. It means that these companies have adapted some strategies to avoid the top price period. The companies of these classes, such as ce- 
ment manufacturing, textile industry, non-metal manufacturing and so on, have little potential to be exploited. The other companies mainly work in triple shift schedule, which constantly works with 24 hours, however the production in the day is still a little higher. If their production could be changed, the adjustable potential are considerable. The refined analysis of load utilization is as the following tables

\section{Conclusion}

Firstly, it was described in this paper that much importance and requirement have been attached to the load data analysis as well as the reference indexes. Then, in view of the rough classification of load data, proposed a weighted fuzzy clustering algorithm to detail the load classification dividing. Two group of experiments are set to verify the efficiency of this method, one of which orients to the difference of load data from one user but different moments, and the other to the difference among different companies but the same day. The experiment results show that the algorithm is effective to accurately cluster the load data and supportive to the fine analysis of load data, promoting the development of electric technology.

\section{Reference}

[1] DONG Rui, HUANG Min-xiang. An improved FCM algorithm based on subtractive clustering for power load classification[J]. East China Electric Power, 2014, 42(5): 917-921.

[2] ZHANG Shao-min, ZHAO Shuo, WANG Bao-yi. Research of power load curve clustering algorithm based on cloud computing and quantum particle swarm optimization[J]. Power System Protection and Control, 2014, 42(21): 93-98.

[3] LIU Yong-guang, Sun Chao-liang, NIU Zhen-zhen, et al. Research on the improved fuzzy Cmeans clustering algorithm based power load characteristic classification technology[J]. Electrical measurement and instrumentation, 2014, 51(18): 5-9.

[4] SONG Yi-yang, LI Cun-bin, QI Zhi-qiang. Extraction of Power Load Patterns Based on Cloud Model and Fuzzy Clustering[J]. Power System Technology, 2014, 38(12): 3378-3383.

[5] Wang Ke, Wang Tian-xiu. Identification of Abnormal Power Load Data Based on Two Times Clustering[J]. Electrical Engineering, 2014, 11:1-3+17.

[6] LI Can-bing, QU Fang, WANG Xiao-ning. Character analysis of power load based on fuzzy clustering[J]. Journal of Zhengzhou University (Engineering Science), 2010, 31(1): 107-110.

[7] JIANG De-long, LI Sheng, WANG Ke-wen, et al. Research and implementation of a fuzzy clustering analysis system[J]. Computer Engineering and Science, 2011, 33(12): 121-125.

[8] LIU Jian-hua, WANG Jin, MENG Ying, et al. Clustering analysis of power load by rough set and K-means based on simulation annealing method[J]. Modern Electric Power, 2012, 29(1): 10-14.

[9] LIU Jian-hua, WANG Jin, YANG Hong-chun et al. Power load clustering analysis based in ACO-PAM synthesis algorithm[J]. Journal of Electric Power Science and Technology, 2011, 26(4): 94-99.

[10]SHI Guo-ping, LIANG Jun, LIU Xiang-sheng. Load Clustering and Synthetic Modeling Based On An Improved Fuzzy C Means Clustering Algorithm[C]. DRPT2008 6-9 July 2011:859-865.

[11]Kamwa, I. Pradhan, A.K. Joos, G. et al. Fuzzy Partitioning of a Real Power System for Dynamic Vulnerability Assessment[J].IEEE Transactions on power systems.24(3):1356-1365.

Jie Fan received her M.S. degree in Dongnan University, China,2014. She is currently the manager of metering department of Jiangsu electric power company research institute. Her research interest focus on demand response, Electric Power Metrology and etc. 